\title{
THE INTERACTION BETWEEN CONTEXT AND GRAMMAR IN FUNCTIONAL DISCOURSE GRAMMAR: INTRODUCTION
}

\author{
Núria Alturo, Evelien Keizer, and Lluís Payrató
}

Functional Discourse Grammar (Hengeveld and Mackenzie 2008) is, as the name suggests, a functional theory of grammar which also takes into consideration aspects of the discourse context in which utterances are used. It is functional in that it assumes that the structure of linguistic utterances is not arbitrary but motivated by the communicative function these utterances fulfil. It is discourse-oriented in that it acknowledges that the structure of utterances can be systematically influenced by the communicative context in which they occur. It is, in other words, assumed that the grammar of a language does not exist in a vacuum and can only be fruitfully studied as part of a wider theory of verbal interaction. Figure 1 illustrates how these assumptions are reflected in the overall organization of the model. In the middle we find the Grammatical Component (the Functional Discourse Grammar, or FDG, itself), which interacts with three other components: A Conceptual Component, a Contextual Component, and an Output Component. These other components are regarded as non-grammatical in that they do not provide (or contain) the grammatical means available in a language to code speaker intention and linguistic meaning. They are, however, linguistic, as far as they have an impact on linguistic form.

Taking a top-down approach, every linguistic communication starts with some communicative intention and its corresponding mental representation at the prelinguistic conceptual level. These intentions, which are contained in the Conceptual Component, trigger the operation of Formulation in the Grammatical Component, which converts them into interpersonal (pragmatic) and representational (semantic) structures. Next, the operation of encoding translates these representations into morphosyntactic and phonological representations, which form the output of the Grammatical Component. This, in turn, forms the input to Output Component, which converts this information into acoustic, orthographic or signed form. This top-down organization of the grammar reflects the idea that "pragmatics governs semantics, pragmatics and semantics govern morphosyntax, and pragmatics, semantics, and morphosyntax govern phonology" (Hengeveld and Mackenzie 2008: 13; see also Section 2.3 below). 


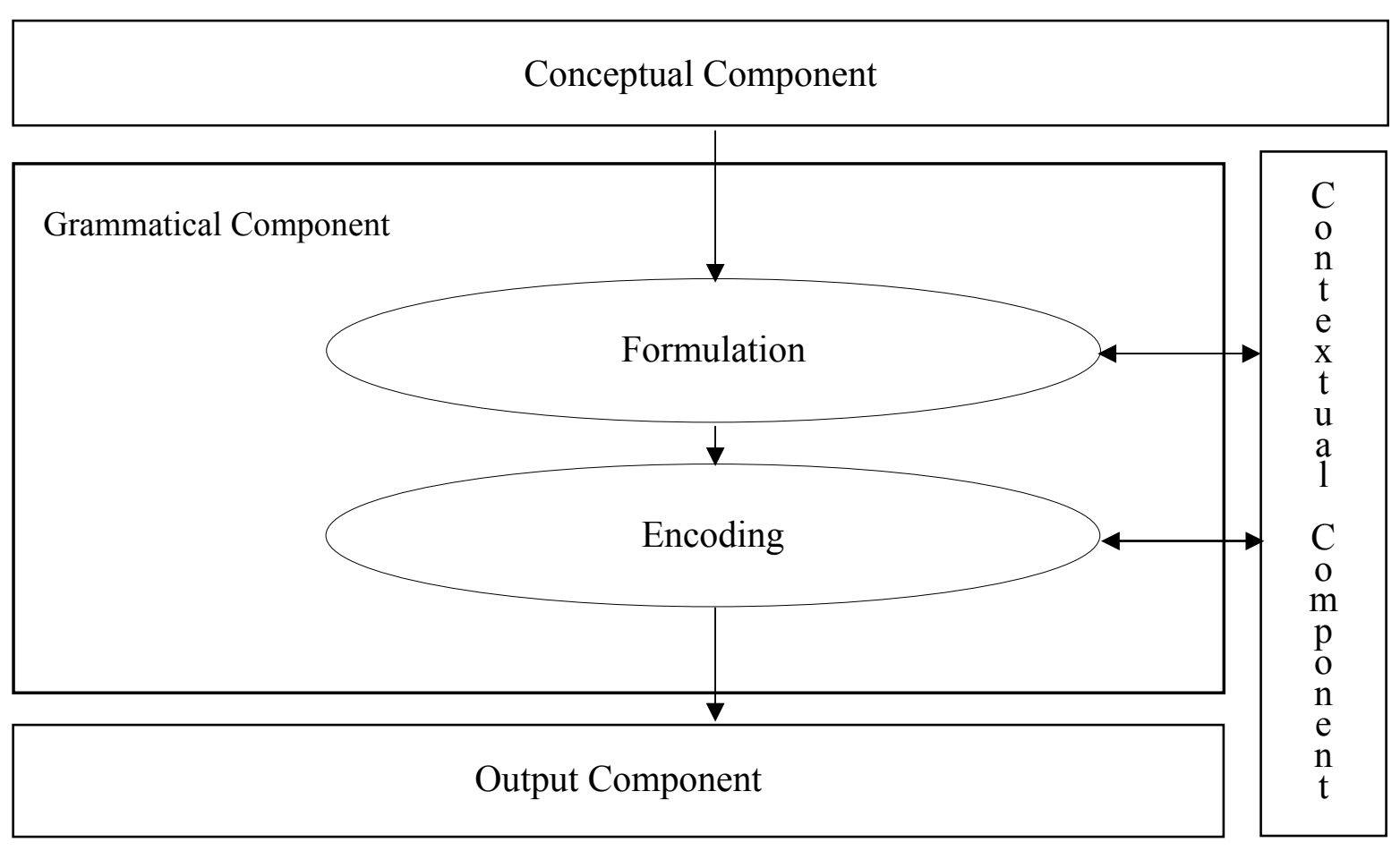

Figure 1: FDG as part of a wider theory of verbal interaction (Hengeveld and Mackenzie 2008: 6)

During the operations of Formulation and Encoding, the Grammatical Component continually interacts with relevant information from the Contextual Component. In some cases, this interaction is relatively straightforward, as, for instance, in the choice of the right deictic pronoun (e.g. he vs. she), or when it comes to the presentation of old vs. new information. What is less clear, however, is exactly which information is present in the Contextual Component, how this contextual information interacts with the grammar, and whether, and if so how, this interaction is mediated through cognition. Currently, the theory of FDG takes a restrictive perspective on what is contained within the Contextual Component, including only "a description of the content and form of preceding discourse and of the actual perceivable setting in which the speech event takes place and of the social relationships between Participants" (Hengeveld and Mackenzie 2008: 6). Other linguists, however, have argued for extending the Contextual Component to also include the surrounding multimodal discourse, the sociocultural context, and the mental representation of context (Connolly 2007, 2010; Rijkhoff 2008; Cornish 2009).

Which contextual information is relevant for linguistic theory relates in the first place to the old problem of the contrast between grammar as a well-defined and articulated system, and context as something "far more amorphous, problematic, and less stable" (Goodwin and Duranti 1992: 13) Should FDG restrict the context (or rather the Contextual Component) to those aspects that influence grammar in a principled and systematic manner, while excluding aspects of the general sociocultural context that do not influence grammar in this way?; or should other aspects of context relevant for multimodal discourse also be included? Secondly, given that in much of the literature 
context is regarded as a cognitive construct (Sperber and Wilson 1986; Givón 2005; Van Dijk 2008; among others), what does this mean for the distinction (and relation) between the Conceptual Component and the Contextual Component in the FDG model of verbal interaction? The contributors to this special issue aim at providing answers to these and related questions by investigating various phenomena in a range of languages.

The remainder of this introduction is organized as follows. Section 1 presents a general overview of the way context has been dealt with within pragmatics. Section 2 offers a brief general introduction to FDG for those readers unfamiliar with the theory. Section 3 discusses the topic of the relationship between context and grammar in FDG, and briefly compares the handling of context in FDG to the way it is handled in what at present is probably the theory closest to FDG in the functional spectrum, Systemic Functional Linguistics. Section 4 provides summaries of the contributions found in this issue.

\section{Context in pragmatics}

General dictionaries of linguistics and specific glossaries of pragmatics tend to define context in two ways, according to the classical and logical concepts of intension and extension. The intensional definition stresses the idea of membership of a set; in the extensional definition the focus is on the individual members of the set. The definitions of context based on the first criterion limit context to "relevant" aspects of the communicative event, i.e. to those features of context that have an impact on grammar. Matthews (2007 [1997]), for example, gives the following very short and (apparently) straightforward definition, based on this notion of relevance. Note, however, that the general definition of context is immediately followed by a distinction between linguistic context and social context, which is a clear drift towards a definition of the second type.

context Any relevant features of the setting in which a form appears or might appear.

$[\ldots]$ The term * co-text is sometimes used of linguistic context as distinct from the wider setting. Hence distinguished from e.g. a 'social context' which would involve the social status of a speaker and an addressee, the social setting in which speech takes place, etc. (Matthews 2007 [1997]: 77)

A clear example of an extensional definition is the one provided by Cruse (2006) in his glossary of semantics and pragmatics:

context An essential factor in the interpretation of utterance and expressions. The most important aspects of contexts are: (1) preceding and following utterances and/or expressions ('co-text'), (2) the immediate physical situation, (3) the wider situation, including social and power relations, and (4) knowledge presumed shared between speaker and hearer (Cruse 2006: 35).

Cruse's definition begins with a general comment on the importance of context; this is followed by the actual definition consisting of a number of specific aspects of context. The selection of these aspects is a delicate matter that any pragmatic theory needs to address. The four aspects mentioned by Cruse appear in almost all approaches to context, including Duranti and Goodwin's (1992) volume on rethinking context, a reader specifically devoted to the topic of context. In their introduction to the volume, 
these authors point out "the range of phenomena that the notion of context must cover" (Goodwin and Duranti 1992: 6):

1. Setting

2. Behavioral environment

3. Language as context

4. Extrasituational context

Sometimes these basic ingredients appear in small variants or are incorporated into other proposals, as in Auer $(1996,2009)$ :

(3) If we are willing to accept a wide notion of context, it is useful to distinguish types of indexed entities in order to come to grips with the complexity of the sign/context interface.

In a pre-theoretical, but intuitively plausible way, five dimensions of context suggest themselves:
a. linguistic contexts (sometimes called co-texts),
b. non-linguistic sense-data in the surroundings of the linguistic activity (the situation in a physical sense),
c. features of the social situation,
d. features of participants' common background knowledge other than (a)-(c), and
e. the channel of communication (the medium).

(Auer 2009: 90-91)

There are, of course, many more studies that deal with the dimensions of context relevant for linguistic analysis, from those that adopt the most restrictive view (where focus is placed on the role on context in the assignment of referential meaning) to those that adopt a broader perspective (where the notion of context is built on the sociocultural and the textual environment and the cognitive abilities that speakers and writers put in play in the act of communication). To name just a few, there is the classical work of Firth (1957), as well as important contributions by Hymes (1972a,b), Brown and Fraser (1979), Goffman (1981, 1986), Gumperz (1982, 1992a,b), Harris (1988), Biber (1988), Devlin (1991), Cook (1992), Linell (1998), Fetzer (2004), Givón (2005), Connolly (2007) and Van Dijk (2008). However, in spite of the wide acceptance of the importance and relevance of context in the study of linguistic phenomena, we are still a long way away from formally incorporating the word context as an unambiguous scientific term. Within pragmatics, even though there seems to be wide agreement on the role played in communication by both 'context of situation' and 'cognitive context' and on the dynamic and multimodal character of context, linguists are still discussing how to account for the link between context and grammar, or, in more formalistic terms, how to model a contextual component that runs parallel with, and constantly interacts with, a grammatical component.

In this respect functional (and cognitive) theories have a clear advantage over other theories, many of which do not even try to take contextual factors into account, regarding context as one of the major (pragmatic) wastebaskets. It is therefore up to the functionally-oriented linguist to show that context is an indispensable ingredient of linguistic theory. As such, the attempt by such linguists to take the role of context seriously is not simply a rerun of the old debate about pragmatics as a component or as a perspective: It is the acknowledgement of the need to formalize the way in which 
context interacts with grammatical knowledge in the production of linguistic utterances, in order to provide the theory not only with a higher degree of descriptive and explanatory adequacy, but also with pragmatic adequacy (Dik 1997a,b). In order to attain pragmatic adequacy, functional theories of language must therefore account for the pragmatic operations taking place in any communicative situation. As already pointed out by Levinson (1983: 21, 24), this inevitably involves taking into account contextual factors, as illustrated by the following three definitions of pragmatics:

(4) a. Pragmatics is the study of the relations between language and context that are basic to an account of language understanding

b. Pragmatics is the study of the role context plays in speaker- (or utterance-) meaning

c. Pragmatics is the study of the ability of language users to pair sentences with the contexts in which they would be appropriate.

Despite this early recognition of the role of context, now, almost thirty years later, linguists are still struggling with the question of how to define context, which types of contextual information to distinguish, which of these types are relevant for linguistic description, and how to incorporate the relevant contextual information into the theory.

\section{A brief introduction to FDG}

FDG (Hengeveld and Mackenzie 2008) is a structural-functional typological model of grammar, intended as the successor to Dik's (1997a,b) Functional Grammar (FG). Although FDG shares many of the basic assumptions and general features of FG, it deviates from Dik's standard theory in a number of important respects (Hengeveld and Mackenzie 2008: 1-12). First of all, unlike FG, FDG has a top-down organization, taking as its starting point the Speaker's intention and then working its way down to articulation. A second new feature of FDG is that it analyses Discourse Acts in terms of independent pragmatic, semantic, morphosyntactic and phonological modules (known as levels), which interact to produce the appropriate linguistic forms. Although still primarily a semantically and pragmatically oriented theory of grammar, FDG thus aims at being comprehensive in dealing with all levels of grammatical organization. Thirdly, FDG is presented as the Grammatical Component of a broader model of verbal communication, in which it systematically interacts with a Conceptual, a Contextual and an Output Component.

FDG's approach to grammar can be placed midway between radical formal and functional models (Hengeveld and Mackenzie 2008: 26-31; see also Butler 2003). FDG can be considered a formal approach in that the theory seeks to specify the overall structure of the grammatical system, but departs from radical formal approaches in that it refuses to limit grammar to the rigidity of covert rules. At the same time, FDG, as a functional approach, accounts for functional variability in grammar, but not to the extreme that grammar emerges as an epiphenomenon of communicative situations (as in Emergent Grammar, Hopper 1987); instead, FDG acknowledges that linguistics utterances reflect restrictions that are imposed by the communicative needs of language users. Within the functional spectrum, FDG can therefore be regarded as situated between, on the formal side, Role and Reference Grammar (RRG; Van Valin and La 
Polla 1997; Van Valin 2005) and, on the functional side, Systemic-Functional Grammar (SFG; Halliday 1985; Halliday and Matthiessen 2004; see Hengeveld and Mackenzie (2008: 26-31) for a brief comparison between FDG; RRG and SFG).

\subsection{Distinctive features of FDG}

As pointed out above, Functional Discourse Grammar (Hengeveld and Mackenzie 2008) combines characteristics of both functional and formal approaches to linguistic analysis. FDG is functional in the sense that "it is based on the belief that the properties of linguistic utterances are adapted to those communicative aims which the language user, in interaction with other language users, seeks to achieve by using those utterances" (Hengeveld and Mackenzie 2008). At the same time, however, FDG describes these properties in a highly formalized way, regarding the grammar of a language (synchronically at least) as a stable system, consisting of systematic oppositions that reflect different communicative intentions. It is this system that FDG tries to describe, which means that it only seeks to account for those communicative intentions that are systematically reflected in morphosyntactic and phonological form (see e.g. Hengeveld and Mackenzie 2008: 39).

As a functional theory of language, FDG seeks to attain both pragmatic and psychological adequacy and to develop a model that is capable of handling discourse rather than sentences. These objectives are clearly reflected in the distinctive features of the model (Hengeveld and Mackenzie 2008: 1-12):

(i) FDG has a top-down organization starting with the encoding of the Speaker's intention and then working its way down to articulation.

(ii) FDG takes the Discourse Act as its basic unit of analysis. As such, FDG can accommodate regular clauses, as well as units larger than the clause (e.g. sequences of sentences), and units smaller than the clause (incomplete utterances and interjections).

(iii) FDG analyses Discourse Acts in terms of independent pragmatic, semantic, morphosyntactic and phonological modules (known as levels), which interact to produce the appropriate linguistic forms. Although still primarily a semantically and pragmatically oriented theory of grammar, FDG thus aims at being comprehensive in dealing with all levels of grammatical organization.

(iv) FDG systematically interacts with a Conceptual, a Contextual and an Output Component within an overall model of verbal communication. The Conceptual Component contains the prelinguistic conceptual information relevant for linguistic analysis and is regarded as the driving force behind the Grammatical Component. The Output Component turns the output of the Grammatical Component into acoustic, orthographic or signed output. Aspects of multimodal communication such as systematic gesture in speech or paragraph structure in writing may also find its place in the Output Component (Hengeveld, seminar in Barcelona, January 2010), although no descriptive work on non-verbal communication has been done so far. The Contextual Component contains non-linguistic information about the immediate discourse context that affects the form of a linguistic utterance. 


\subsection{The grammatical component}

To capture the top-down organization in the analysis of linguistic expressions, the grammar is conceived of as consisting of four different levels of representation (the rectangles in Figure 2). At the top we find the Interpersonal Level, which is meant to capture all the linguistically coded aspects of an utterance that relate to the interaction between a Speaker and a Hearer. The Interpersonal Level is a strategic level, specifying the actions performed by the Speaker in building up a linguistic utterance. The next level is the Representational Level, which is concerned with the relation that obtains between language and the world it describes. This level deals with the semantic aspects of an expression, irrespective of the context in which it is used.

The Interpersonal and Representation Levels are the outcome of the operation of Formulation: Together these levels contain all the pragmatic, rhetorical and semantic aspects of a linguistic expression for which the grammar of the language in question provides a systematic way of encoding. The remaining two levels, brought about during the operation of Encoding, specify the exact way in which this interpersonal and representational material is encoded. At the first of these, the Morphosyntactic Level, the input from the Interpersonal and Representational Levels is merged into a single structural unit. This information is then fed into the Phonological Level, which serves to generate the final phonemic form of an utterance.

Despite the obvious differences between the four levels, there are also systematic correspondences between them. Thus, at each level, the construction of a linguistic expression begins with the selection of a number of (language-specific) primitives (the boxes in Figure 2). These primitives come in three kinds. First, there are the structuring primitives, which define the possible combinations of elements at each level. At the Interpersonal and Representational Levels these take the form of frames, at the Morphosyntactic and Phonological Level that of templates. The second set of primitives consists of the relevant linguistic elements at each level: The lexemes used in formulation, the grammatical morphemes used in morphosyntactic encoding, and the (suppletive) phonemic forms used in phonological encoding. Finally, each level has its own set of operators, representing grammatically expressed information.

Furthermore, each of the four levels of representation is hierarchically organized, consisting of several layers, each provided with a variable which is restricted by a head. At the Interpersonal and Representational Levels, each layer further contains a position for modifiers, which provide optional lexical information. The general structure of each layer can be represented as follows (where $\alpha_{1}$ represents the variable at the relevant layer, $\pi_{1}$ one or more operators, and $\sigma_{1}$ one or more modifiers) (Hengeveld and Mackenzie 2008: 14):

$$
\left(\pi_{1} \alpha_{1}:\left[\text { head] }\left(\alpha_{1}\right): \sigma_{1}\left(\alpha_{1}\right)\right)\right.
$$

Since FDG only represents information that is linguistically coded, not all layers need to be present in every act of verbal communication. 


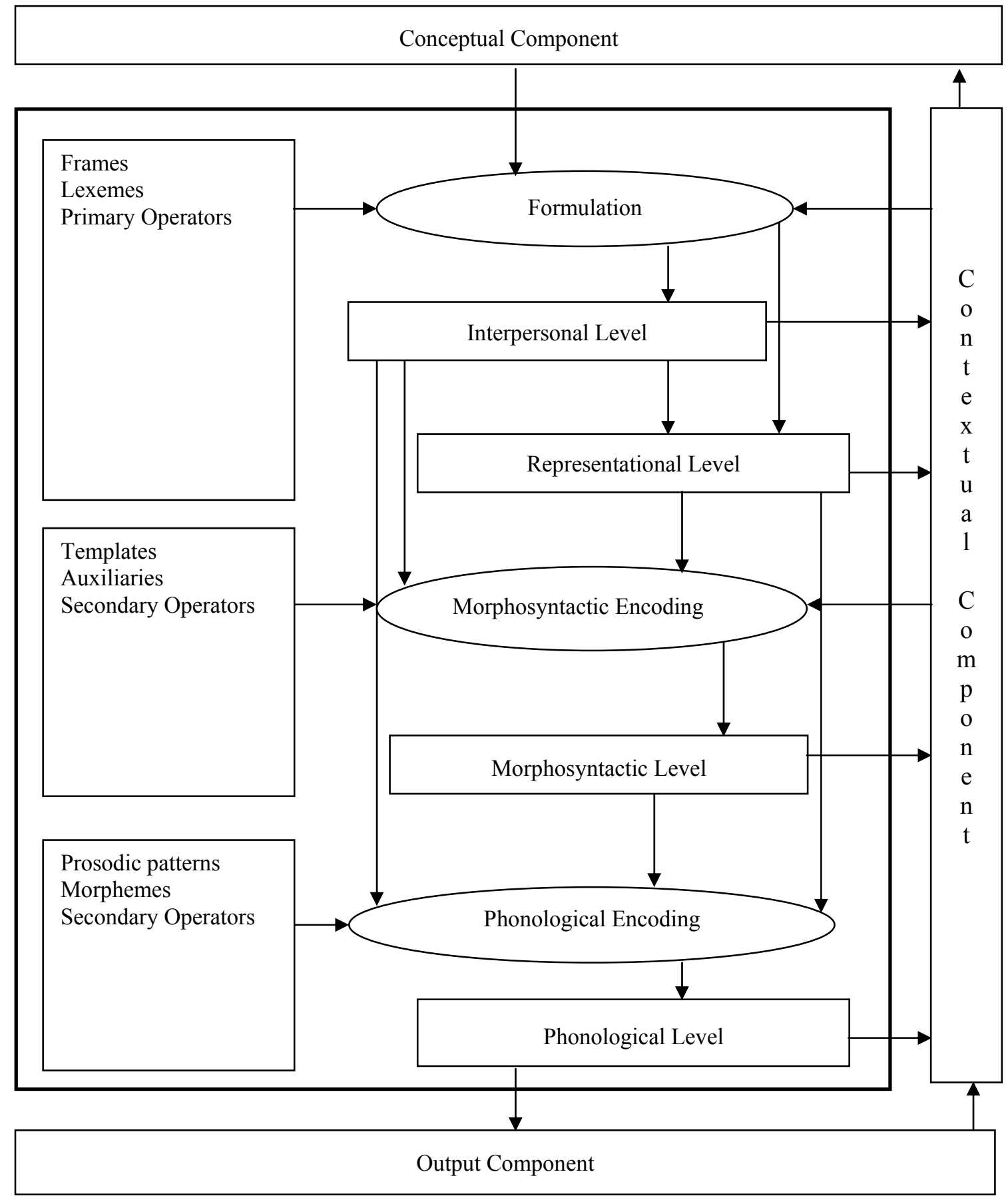

Figure 2: FDG: general layout

To give an impression of what the underlying representations in FDG look like, let us analyse one simple expression: The phrase these bananas in the sentence in (6) (from Hengeveld and Mackenzie 2008: 23).

(6) (I like) these bananas. 
This phrase will be given the following representations at each of the four levels of analysis:

\begin{tabular}{|l|l|}
\hline Interpersonal Level & $\left(+\mathrm{id} \mathrm{R}_{\mathrm{I}}\right)$ \\
\hline Representational Level & $\left(\right.$ prox m x $_{\mathrm{i}}:\left[\left(\mathrm{f}_{\mathrm{i}}:\right.\right.$ banana $\left.\left.\left._{\mathrm{N}}\left(\mathrm{f}_{\mathrm{i}}\right)\right)\left(\mathrm{x}_{\mathrm{i}}\right)_{\Phi}\right]\right)$ \\
\hline Morphosyntactic Level & $\left(\mathrm{Np}_{\mathrm{i}}:\left[\left(\mathrm{GW}_{\mathrm{i}}:\right.\right.\right.$ this-pl $\left.\left(\mathrm{GW}_{\mathrm{i}}\right)\right)\left(\mathrm{Nw}_{\mathrm{i}}: / \mathrm{b}^{\prime}\right.$ na:nə/-pl $\left.\left.\left.\left.\left(\mathrm{NW}_{\mathrm{i}}\right)\right)\right] \mathrm{Np}_{\mathrm{i}}\right)\right)$ \\
\hline Phonological Level & $\left(\mathrm{PP}_{\mathrm{i}}:\left[\left(\mathrm{PW}_{\mathrm{i}}: / \partial \mathrm{di} / \mathrm{z} /\left(\mathrm{PW}_{\mathrm{i}}\right)\right)\left(\mathrm{PW}_{\mathrm{j}}: / \mathrm{b}^{\prime}\right.\right.\right.$ 'na:nəz/ $\left.\left.\left.\left(\mathrm{PW}_{\mathrm{j}}\right)\right)\right]\left(\mathrm{PP}_{\mathrm{i}}\right)\right)$ \\
\hline
\end{tabular}

At the Interpersonal Level, the phrase these bananas is analysed as a referential expression $(\mathrm{R})$ whose referent is assumed by the Speaker to be identifiable $(+\mathrm{id})$ for the Addressee. The representation at the Representational Level captures the fact that the referent is a plural set $(\mathrm{m})$ of concrete entities ( $\mathrm{x}$ ) with the property 'banana' (f) which is located in the vicinity of the Speaker ('prox'). At the Morphosyntactic Level the phrase these bananas is characterized as being a Noun Phrase (Np) consisting of a Grammatical Word (Gw) and a Nominal Word (Nw). At this level, the operators ' $\mathrm{m}$ ' and 'prox' are converted and represented as morphosyntactic operators which function as placeholders ('pl' and 'this', respectively). At the Phonological Level the appropriate plural forms of the Words are introduced, together these two Words (PWs) form one Phonological Phrase (PP).

Of the four levels only the Interpersonal and the Phonological Levels are obligatorily present in the production of a linguistic utterance. Thus a vocative element like Hey!, lacking semantic content and morphosyntactic structure, is anaysed only at the Interpersonal Level (as the direct instantiation of the Illocution, $\mathrm{F}_{\mathrm{I}}$ ) and at the Phonological Level (as a complete Intonational Phrase, $\mathrm{IP}_{\mathrm{I}}$ ):

\begin{tabular}{|l|l|}
\hline Interpersonal Level & $\left(\mathrm{F}_{\mathrm{I}}:\right.$ hey $\left.\left(\mathrm{F}_{\mathrm{I}}\right)\right)$ \\
\hline Phonological Level & $\left(\mathrm{IP}_{\mathrm{I}}:\left(\mathrm{PP}_{\mathrm{i}}:\left(\mathrm{PW}_{\mathrm{i}}: /\right.\right.\right.$ heI $\left.\left.\left./\left(\mathrm{PW}_{\mathrm{i}}\right)\right)\left(\mathrm{PP}_{\mathrm{i}}\right)\right)\left(\mathrm{IP}_{\mathrm{i}}\right)\right)$ \\
\hline
\end{tabular}

\section{Context in Functional Discourse Grammar}

\subsection{The interaction between context and grammar}

Any functional theory of language takes for granted that contextual information, in its different dimensions and manifestations (see Section 1), plays an important role in the production and interpretation of linguistic utterances. What is not so clear, however, is (i) how much of this contextual information is relevant for linguistic description (i.e. which information goes into the Contextual Component) and (ii) how this information interacts with the four levels of analysis that make up the grammar of a language.

With regard to the first question, it is important to realize that (standard) FDG does not aim at providing a complete description of all the possible aspects of context that may in some way influence a Speaker's linguistic contribution. Thus, although contextual information undeniably comes in many different types, Hengeveld and Mackenzie (2008: 9) conceive of the Contextual Component as containing only two types of contextual information: (i) immediate (short-term) information from the Grammatical Component concerning particular utterances (e.g. referents introduced in previous discourse); this information needs to be continually kept up to date; (ii) longterm information about the ongoing interaction (e.g. immediate situational information, 
including gender of the speech participants, as well as the social relationships between them) (Hengeveld and Mackenzie 2008: 9-10, this issue). In deciding what is and what is not part of the Contextual Component, FDG thus adopts what Butler (2008) describes as a 'conservative stance', including only that information which "can be shown to have a systematic effect upon the grammatical choices" made by the speaker during the operation of Formulation (Hengeveld and Mackenzie 2008: 10). However, although elaborations of the standard view, as well as alternative accounts of what should be included in the Contextual Component have been proposed (e.g. Connolly 2004, 2007, 2010; Butler 2008; Cornish 2009; Rijkhoff 2008), there has been no coordinated attempt to specify the internal organization of the Contextual Component or the exact nature of its interaction with the Grammatical Component. The contributions in this issue aim to further develop this aspect of the theory.

As for the second question, it is assumed that the Contextual Component interacts with the Grammatical Component during the various stages of the model: As indicated by the arrows in Figure 1, information from each of the four levels of representation feeds into the Contextual Component, while information from the Contextual Component enters the Grammatical Component during the operations of Formulation and Encoding. How exactly this interaction takes place is another question that still remains to be answered, as is the question of the interaction between the Contextual Component and the Conceptual Component.

FDG's view of context is broadly consistent with the current view of context in other cognitive and functional theories of language, even though there are differences in focus that are reflected in the architecture of each individual model. FDG shares with other proposals, for instance, the view that context is mediated through cognition (Van Dijk 2008; Sperber and Wilson 1986; Wilson and Sperber 2004). However, whereas Van Dijk (2008) emphasizes the cognitive processing of contexts, FDG proposes a clear distinction between cognition and context: It argues for a separate Conceptual Component that contains the Speaker's intended message (the prelinguistic conceptual information relevant for linguistic analysis), while the Contextual Component allows for the storage and retrieval of contextual properties relevant to grammar. Moreover, in FDG the Contextual Component contains only those properties of the ongoing communicative situation that are relevant for the speech participants, which is a generally accepted view in the literature, particularly since Relevance Theory (Sperber and Wilson 1986). Finally, while some theories of context include all the social and cultural factors relevant to a particular communicative situation (Goodwin and Duranti 1992; Fetzer 2004; Halliday and Matthiessen 2004; Martin and Rose 2007, 2008; Van Dijk 2008), the Contextual Component in FDG contains only those social and cultural aspects that have a systematic impact on grammatical form.

\subsection{The role of context: FDG and SFG compared}

As we have just seen, FDG makes a principled distinction between context (i.e. all the contextual information available to the speech participants in a certain communicative setting) and the Contextual Component, which only includes that contextual information that is relevant for the operations of Formulation and Encoding in the Grammatical Component. At the same time, the Contextual Component provides storage space for the results of these operations at all levels of grammar: Interpersonal (pragmatic), 
representational (semantic), morphosyntactic and phonological. As the ongoing discourse unfolds, the Contextual Component of grammar is constantly updated, and available for both production and interpretation, in monological and dialogical discourse, while also affecting an individual's articulation of grammar in the Output Component. Each language, or grammar system, has its own Contextual Component, which captures the fact that languages are sensitive in different ways to the impact of context (as in the case of honorifics and grammatical gender, for instance).

This view departs from Systemic-Functional Grammar (SFG, Halliday 1985; Halliday and Matthiessen 2004) - the model closest to FDG in the functional spectrum - in that in FDG the focus is on grammatical reflections of social meanings, whereas in SFG the focus is on the individual's use of language in social contexts. Moreover, SFG takes the text as the object of linguistic analysis, looking at individual sentences in terms of the contribution they make to the larger whole. By contrast, in FDG the basic unit of analysis is the Discourse Act (the minimal unit of communication), which can be combined into Moves that are intentionally motivated and interactionally driven. (Hengeveld and Mackenzie 2008: 29).

These different perspectives can be observed in the formal modeling of SFG and FDG. SFG's functional diversification (field-ideational, tenor-interpersonal, modetextual) and stratification (context of register, semantics, lexicogrammar), for instance, are captured in FDG through a psychologically based model of language processing (inspired by Levelt 1989): In FDG, functional variation and stratification are modeled through a top-down architecture that departs from the speaker's intentions at the Conceptual Component and which is gradually given shape at the different levels in the Grammatical Component (Hengeveld and Mackenzie 2008), in interaction with the corresponding strata in the Contextual Component (Hengeveld and Mackenzie, this issue).

Another difference between the two theories concerns the distinction between semantics and pragmatics. Thus, in SFG, for instance, both speech functions (asking, giving information, etc.) and the participants involved in a process (actor, location, etc.) belong to semantics, and their particular roles come from the contextual features of tenor (for speech functions) and field (for participants in a process), which are related to the interpersonal and the ideational metafunctions, respectively. By contrast, FDG accounts for speech functions as pragmatic components of Discourse Acts that capture "the lexical and formal properties of that Discourse Act that can be attributed to its conventionalized interpersonal use in achieving a communicative intention", that is, as illocutions at the pragmatic (interpersonal) level (Hengeveld and Mackenzie 2008: 68). Speech functions (Illocutions of Discourse Acts in FDG), then, do not rely on contextual features, but on the intentions in the minds of language users, regardless of the role context might play in the mental configuration of those intentions.

Participants involved in a process, on the other hand, are placed within semantics (the Representational Level) in FDG, as in SFG, but not as material options depending on the process type (as in SFG), but as semantic functions assigned to the arguments of properties, i.e. to dependent units in a predication frame. These functions are not conceived of as options in the system, but as "grammatical reflexes of the cognitive awareness that the participants in a State-of-Affairs (i) play different roles in that State-of-Affairs (in which case the State-of-Affairs is treated in grammar as Property); (ii) play the same role in the State-of-Affairs (in which case the State-ofAffairs is treated as a classification or identification); (iii) cannot be seen as playing a 
role in a State-of-Affairs (in which case that State-of-Affairs is presented in a predication of existence)" (Hengeveld and Mackenzie 2008: 195).

Finally, whereas SFG looks at general social aspects when identifying contextual features of instances of language use (such as genre or ethnic identities), FDG places these features outside the grammar's Contextual Component, unless they have a systematic structural effect.

The Contextual Component in FDG, then, is restricted to discourse context (the information that has been formulated or encoded in the Grammatical Component and is found in the co-text and the inter-text) and situational context (i.e. what is generally referred to in pragmatics literature as immediate context), both of which belong to the extra-mental, perceived, context. Communicative intentions, by contrast, belong to the Conceptual Component. Other aspects of context (stored knowledge, relevance, single or joined context, context mental information, inferences) do not seem to belong to either of these components and could be thought of as being situated at the interface between the Conceptual and the Contextual Components.

\section{The contributions}

The paper by Kees Hengeveld and Lachlan Mackenzie, "Grammar and Context in Functional Discourse Grammar", provides an extension of their standard work (Hengeveld and Mackenzie 2008) by presenting a general overview of the interaction between the Contextual and the Grammatical Components. The authors' approach can be described as minimalistic in the sense that they regard the Contextual Component as including only that non-linguistic information that has a systematic influence on the linguistic form of an utterance. The paper offers a proposal for the internal organization of the Contextual Component that parallels the multilevel architecture of FDG. The discussion focuses on three different issues: Where the Contextual Component obtains its information from; how contextual information enters the grammar; and how old information fades out and new information comes to the fore in a dynamic view of the contextual component. The workings of the proposal are demonstrated by the analysis of unexpressed arguments in Turkish, the use of English too, and the answers to yes/no questions in European Portuguese.

John Connolly's paper “The Contextual Component within a Dynamic Implementation of the FDG Model: Structure and Interaction" is also concerned with the question of what kind of information needs to be included in the Contextual Component. Connolly, however, takes a very inclusive view, specifying in detail the way in which the many different types of contextual knowledge are organized within the Contextual Component. The architecture of the Contextual Component he proposes aims both to support a dynamic implementation of FDG and to accommodate the process of multimodal discourse. Furthermore, Connolly looks at the nature of the interaction between the components of the FDG model and suggests that this interaction proceeds in a cyclical manner, where the Conceptual Component plays a mediating role between the Contextual Component (discoursal and situational) and the Grammatical Component.

These first two papers present two rather different views on which information belongs in the Contextual Component. As such, they form excellent points of reference for the remaining papers, which deal with specific constructions and phenomena from a 
number of languages demonstrating the impact of contextual information on the form of linguistic utterances.

In "The Contextual Component in a dialogic FDG", Lachlan Mackenzie argues for a truly dynamic Contextual Component in a dialogic FDG. At the moment, Mackenzie points out, the component is somewhat disembodied, interacting in a rather static way with the grammar of one participant only. Instead, he proposes that the Contextual Component should be seen as linking the Grammatical Components of two participants, representing the free flow of information between speakers. The proposed dialogic FDG provides a basis for understanding the role of interpersonal alignment in conversation as well as reflecting developments in psycholinguistics.

In Riccardo Giomi's paper "Grammar, context and the hearer: A proposal for an addressee-oriented model of Functional Discourse Grammar", the focus shifts to the hearer's perspective. Giomi builds on the idea of a dialogic grammar envisaged by Mackenzie, concentrating, however, on the role of the hearer. His work supports a closer interaction between the Conceptual Component (as conceived by Connolly) and the Contextual Component than it is described in previous FDG's literature, and opens the door to a formal treatment of many inferential, usage-based processes which have traditionally been excluded from FDG accounts.

In "Activation and the relation between context and grammar", Daniel García Velasco regards activation and sharedness as mental processes which serve to focus the speech participants' attention on specific entities and common knowledge. Contrary to the current FDG view, García Velasco argues that activation and sharedness (represented in the Conceptual Component, but triggered by contextual information) have systematic morphosyntactic correlates and should therefore be represented in the grammar. He argues that since activation and sharedness play a role in the pragmatic structuring of discourse, they best be analysed as pragmatic functions belonging to the realm of givenness. García Velasco further argues that givenness relates to the dynamic temporal dimension of discourse, as opposed to the static form-oriented notion of aboutness, to which other pragmatic functions in FDG relate (Topic/Comment; Focus/Background; Contrast/Overlap; see also Keizer's (this volume) multifaceted approach to activation).

Freek van de Velde's paper on Dutch nominalizations ("The discourse motivation for split-ergative alignment In Dutch nominalisations (and elsewhere)") is in line with a long-standing interest in nominalization in F(D)G. Van de Velde uses the observation that Dutch nominalizations have ergative tendencies to argue that argument realization in Dutch nominalizations is motivated by contextual factors: It is on the basis of contextual information (information status of the arguments) that Dutch speakers choose either ergative or accusative alignment in the formation of nominalizations. He concludes that nominalizations can be considered as instructions to the addressee to retrieve semantic units from the Contextual Component.

In "Humming, whistling, singing, and yelling in Pirahã. Context and channels of communication in FDG", Gareth O'Neill investigates the interaction between the Contextual Component and the Phonological Level. O'Neill looks at the different channels of communication in the Brazilian Amazon language Pirahã (normal speech, hum speech, musical speech, whistle speech and yell speech, each with their own phonological form), examining the impact of specific contextual factors on the operations of Formulation, Encoding and Articulation. More specifically, the paper 
considers the possibility of distinguishing between an underlying and a surface phonological form.

John Connolly, in a second contribution ("Recontextualisation, resemiotisation and their analysis in terms of an FDG-based framework"), evaluates the adequacy of FDG in handling a particular aspect of context, namely recontextualization (the process whereby content expressed in one context is subsequently reused and expressed in a different context) and the subsequent process of resemiotisation (the recasting of information in the process of recontextualisation). In particular, Connolly considers the question of how the textual differences between source text and destination text relate to the contextual differences between the two texts.

Evelien Keizer's paper, "Context and cognition in Functional Discourse Grammar: What, where and why?", closes the compilation with a thorough discussion of one of the fundamental issues that have been raised in the previous papers: The interaction between the Grammatical, the Conceptual and the Contextual Components. She investigates the role of contextual information (in particular the notion of Speaker's perspective) in determining the choice of a particular construction in the active-passive alternation. The discussion of this alternation allows Keizer to address a number of essential questions concerning the relation between the Contextual and Grammatical Components, e.g. which contextual information is represented in the Grammatical Component and which information is not; and at which stage does interaction take place (during Formulation, during Encoding, or through the Conceptual Component; see also García Velasco, this issue).

\section{References}

Auer, Peter (1996) From context to contextualization. Links \& Letters 3: 11-28.

Auer, Peter (2009) Context and contextualization. In J. Verschueren, and J.O. Östman (eds.), Key Notions for Pragmatics. Amsterdam: John Benjamins Publishing Company, pp. 86-101.

Biber, Douglas (1988) Variation across Speech and Writing. Cambridge: Cambridge University Press.

Brown, Penelope, and Colin Fraser (1979) Speech as a marker of situation. In K. Scherer, and H. Giles (eds.), Social Markers in Speech. Cambridge: Cambridge University Press, pp. 33-62.

Butler, Christopher S. (2003) Structure and Function: A Guide to Three Major Structural-Functional Theories. Amsterdam: John Benjamins Publishing Company.

Butler, Christopher S. (2008) Interpersonal meaning in the noun phrase. In D. García Velasco, and J. Rijkhoff (eds.), The Noun Phrase in Functional Discourse Grammar. Berlin: Mouton de Gruyter, pp. 221-261.

Connolly, John H. (2004) The question of discourse representation in Functional Discourse Grammar. In J.L. Mackenzie, and M.A. Gómez-González (eds.), A New Architecture for Functional Grammar. Berlin: Mouton de Gruyter, pp. 89-116.

Connolly, John H. (2007) Context in Functional Discourse Grammar. Alfa: Revista de Lingüística 51/2: 11-33. 
Connolly, John H. (2008) Freestanding noun phrases within documents: A pragmatic approach based on Functional Discourse Grammar. In D. García Velasco, and J. Rijkhoff (eds.), The Noun Phrase in Functional Discourse Grammar. Berlin: Mouton de Gruyter, pp. 263-285.

Connolly, John H. (2010) Accommodating multimodality in Functional Discourse Grammar. In G. Wanders, and E. Keizer (eds.), Web Papers in Functional Discourse Grammar 83: 1-18. Available at http://home.hum.uva.nl/fdg/working_papers/WP-FDG-83_Connolly.pdf

Cook, Guy (1992) The Discourse of Advertising. London: Routledge.

Cornish, Francis (2009) Text and discourse as context: Discourse anaphora and the FDG Contextual Component. In E. Keizer, and G. Wanders (eds.), Special Issue: The London papers I. Web Papers in Functional Discourse Grammar, pp. 97-115.

Cruse, Alan (2006) A Glossary of Semantics and Pragmatics. Edinburgh: Edinburgh University Press.

Devlin, Keith (1991) Logic and Information. Cambridge: Cambridge University Press.

Dik, Simon C. (1997a) The Theory of Functional Grammar. Part 1: The Structure of the Clause. Edited by K. Hengeveld. Berlin: Mouton de Gruyter.

Dik, Simon C. (1997b) The Theory of Functional Grammar. Part 2: Complex and Derived Constructions. Edited by K. Hengeveld. Berlin: Mouton de Gruyter.

Duranti, Alessandro, and Charles Goodwin (1992) (eds.) Rethinking context: Language as an interactive phenomenon. Cambridge: Cambridge University Press.

Fetzer, Anita (2004) Recontextualizing Context: Grammaticality Meets Appropiateness. Amsterdam: John Benjamins Publishing Company.

Firth, John R. (1957) Papers in Linguistics 1934-1951. London: Oxford University Press.

Givón, Talmy (2005) Context as Other Minds. The Pragmatics of Sociality, Cognition and Communication. Amsterdam: John Benjamins Publishing Company.

Goffman, Ervin (1981) Forms of Talk. Oxford: Blackwell.

Goffman, Ervin (1986) Frame Analysis: An Essay on the Organisation of Experience. Boston: Northeastern University Press.

Goodwin, Charles, and Alessandro Duranti (1992) Rethinking context: An introduction. In A. Duranti, and C. Goodwin (eds.), Rethinking Context: Grammaticality Meets Appropriateness. Amsterdam: John Benjamins Publishing Company, pp. 1-43.

Gumperz, John J. (1982) Discourse Strategies. Cambridge: Cambridge University Press.

Gumperz, John J. (1992a) Contextualization revisited. In P. Auer, and A. Di Luzio (eds.), The contextualization of language. Amsterdam: John Benjamins Publishing Company, pp. 39-54.

Gumperz, John J. (1992b) Contextualization and understanding. In A. Duranti, and C. Goodwin (eds.), Rethinking Context: Grammaticality Meets Appropriateness. Amsterdam: John Benjamins Publishing Company, pp. 229-252.

Halliday, M.A.K. (1985) An Introduction to Functional Grammar. London: Edward Arnold.

Halliday, M.A.K., and Christian M.I.M. Matthiessen (2004) An Introduction to Functional Grammar (3 ${ }^{\text {rd }}$ revised edition on Halliday 1985). London: Hodder Arnold. 
Harris, Wendell V. (1988) Interpretive Acts: In Search of Meaning. Oxford: Clarendon.

Hengeveld, Kees, and John L. Mackenzie (2008) Functional Discourse Grammar. Oxford: Oxford University Press.

Hopper, Paul (1987) Emergent grammar. Berkeley Linguistics Society 13: 139-157.

Hymes, Dell (1972a) Models of the interaction of language and social life. In J.J. Gumperz, and D. Hymes (eds.), Directions in Sociolinguistics: The Ethnography of Communication. New York: Holt Rinehart and Winston, pp. 35-71.

Hymes, Dell (1972b) On communicative competence. In J.B. Pride, and J. Holmes (eds.), Sociolinguistics. Harmondsworth: Penguin, pp. 269-283.

Levelt, Willem J.M. (1989) Speaking. Cambridge, MA: MIT Press.

Levinson, Stephen C. (1983) Pragmatics. Cambridge: Cambridge University Press.

Linell, Per (1998) Approaching Dialogue: Talk, Interaction and Contexts in Dialogical Perspectives. Amsterdam: John Benjamins Publishing Company.

Martin, J.R., and David Rose (2007) Working with Discourse (2nd edition). London: Continuum.

Martin, J.R., and David Rose (2008) Genre Relations: Mapping Culture. London: Equinox.

Matthews, Peter H. (2007) The Concise Oxford Dictionary of Linguistics. Oxford: Oxford University Press ( $1^{\text {st }}$ edition, 1997).

Ochs, Elinor (1979) Introduction: What child language can contribute to pragmatics. In E. Ochs, and B.B. Schieffelin (eds.), Developmental Pragmatics. New York: Academic Press, pp. 1-17.

Rijkhoff, Jan (2008) Layers, levels and contexts in Functional Discourse Grammar. In D. García Velasco, and J. Rijkhoff (eds.), The Noun Phrase in Functional Discourse Grammar. Berlin: Mouton de Gruyter, pp. 63-115.

Sperber, Dan, and Deirdre Wilson (1986) Relevance: Communication and Cognition. Oxford: Blackwell.

Van Dijk, Teun A. (2008) Discourse and Context: A Sociocognitive Approach. Cambridge: Cambridge University Press.

Van Valin, Jr, Robert D. (2005) Exploring the Syntax-Semantics Interface. Cambridge: Cambridge University Press.

Van Valin, Jr, Robert D., and Randy La Polla (1997) Syntax: Structure, Meaning and Function. Cambridge: Cambridge University Press.

Wilson, Deirdre, and Dan Sperber (2004) Relevance theory. In L.R. Horn, and G. Ward (eds.), The Handbook of Pragmatics. Oxford: Blackwell, pp. 607-632.

NÚRIA ALTURO is Associate professor of Catalan linguistics at Universitat de Barcelona. Her research interest focuses on the pragmatics and semantics of linguistic expressions, hand gestures, and discourse 
structures from a functional approach. Within the framework of Functional Discourse Grammar, she has worked on pragmatic functions, reference, coherence, and cohesion (e.g. "La motivació pragmàtica de la cohesió en la conversa", Caplletra 49: 9-26, 2010, with Kees Hengeveld). Currently, she is head researcher of the project "Cohesion and argumentation in conversational genres (COHARGUMENT)" (FFI2011-25236).

Address: Departament de Filologia Catalana, Universitat de Barcelona, Gran Via de les Corts Catalanes 585, E-08007 Barcelona. E-mail: nalturo@ub.edu.

EVELIEN KEIZER is Chair of English linguistics at the University of Vienna. Her main interest is in the interplay between the discourse-pragmatic, semantic, syntactic and phonological properties of linguistic expressions. The overall approach is a functional-cognitive one; more specifically she works within the framework of Functional Discourse Grammar. She has published widely on the noun phrase in English (e.g. The English Noun Phrase. The nature of linguistic categorization, 2007, OUP) and Dutch (Syntax of Dutch: The Noun Phrase, Vol. 1, 2011, AUP). Her current research interests include syntactic alternations, linguistic categorization and the analysis of semi-fixed expressions.

Address: University of Vienna, Department of English, Spitalgasse 2-4/Hof 8.3, 1090, Wien, Austria. E-mail: evelien.keizer@univie.ac.at.

LLUÍS PAYRATÓ is Professor at the Department of Catalan Linguistics at Universitat de Barcelona. His research interests and publications are centred on pragmatics, discourse analysis, non-verbal communication, language contact, and colloquial discourse. Among his publications in English are "Towards a pragmatic approach to the study of languages in contact", in collaboration with J.A. Argente, Pragmatics 1 (1991); "A pragmatic view on autonomous gestures, Journal of Pragmatics 20 (1993); "Communicative strategies and sociocultural identities in talk shows" (in collaboration with a research team), Pragmatics 3 (1995); "Non-verbal communication", in J. Verschueren, and J.-O. Östman (eds.): Key notions for pragmatics (Amsterdam: John Benjamins Publishing Company); and, with J.M. Cots (eds.) (2011): The pragmatics of Catalan (Boston: Mouton de Gruyter).

Address: Departament de Filologia Catalana, Universitat de Barcelona, Gran Via de les Corts Catalanes 585, E-08007 Barcelona. E-mail: payrato@ub.edu. 